\title{
Factors Influencing the Adoption of Health Information Standards in Health Care Organizations: A Systematic Review Based on Best Fit Framework Synthesis
}

Lu Han ${ }^{1}$, BSc; Jing Liu ${ }^{1}$, MSc; Richard Evans ${ }^{2}$, Dr med; Yang Song ${ }^{1}$, BSc; Jingdong Ma ${ }^{1}$, Dr med

${ }^{1}$ School of Medicine and Health Management, Tongji Medical College, Huazhong University of Science and Technology, Wuhan, China

${ }^{2}$ College of Engineering, Design and Physical Sciences, Brunel University London, London, United Kingdom

Corresponding Author:

Jingdong Ma, Dr med

School of Medicine and Health Management

Tongji Medical College

Huazhong University of Science and Technology

No 13 Hangkong Road

Qiaokou District

Wuhan, 430030

China

Phone: 862783692826

Email: jdma@hust.edu.cn

\begin{abstract}
Background: Since the early 1970s, health care provision has experienced rapid growth in the investment and adoption of health information technologies (HITs). However, the development and deployment of HITs has often been conducted in silos, at different organizational levels, within different regions, and in various health care settings; this has resulted in their infrastructures often being difficult to manage or integrate. Health information standards (ie, the set norms and requirements that underpin the deployment of HITs in health care settings) are expected to address these issues, yet their adoption remains to be frustratingly low among health care information technology vendors.
\end{abstract}

Objective: This study aimed to synthesize a comprehensive framework of factors that affect the adoption and deployment of health information standards by health care organizations.

Methods: First, electronic databases, including Web of Science, Scopus, and PubMed, were searched for relevant articles, with the results being exported to the EndNote reference management software. Second, study selection was conducted according to pre-established inclusion and exclusion criteria. Finally, a synthesized best fit framework was created, which integrated a thematic analysis of the included articles.

Results: In total, 35 records were incorporated into the synthesized framework, with 4 dimensions being identified: technology, organization, environment, and interorganizational relationships. The technology dimension included relative advantage, complexity, compatibility, trialability, observability, switching cost, standards uncertainty, and shared business process attributes. The organization dimension included organizational scale, organizational culture, staff resistance to change, staff training, top management support, and organizational readiness. The environment dimension included external pressure, external support, network externality, installed base, and information communication. Finally, the interorganizational relationships dimension included partner trust, partner dependence, relationship commitment, and partner power.

Conclusions: The synthesized framework presented in this paper extends the current understanding of the factors that influence the adoption of health information standards in health care organizations. It provides policy and decision makers with a greater awareness of factors that hinder or facilitate their adoption, enabling better judgement and development of adoption intervention strategies. Furthermore, suggestions for future research are provided.

(JMIR Med Inform 2020;8(5):e17334) doi: 10.2196/17334

\section{KEYWORDS}

health information systems; health information interoperability; adoption; health care sector 


\section{Introduction}

\section{Background}

During the last 50 years, the health care sector has experienced rapid technological growth, with the investment and adoption of health information technologies (HITs) showing promise to increase patient safety, reduce medical errors, improve efficiency, and reduce overall costs. However, health care systems are inherently complex, incorporating numerous interrelated and independent components [1]. A plethora of HITs exist across different levels of health care organizations [2]; however, underlying infrastructural issues have caused a multitude of integration and management issues [3]. This has resulted in many limitations, resulting in organizations not reaping the adoption benefits that were once promised, in particular, reduction in medical service costs [4]. For this reason, HITs should be adopted in a way that creates interoperability with other health care systems, enabling organizations to realize such benefits [5]. This can be resolved through the implementation of consensus standards [6]. The use of consensus standards is based on the idea of developing an agreed set of specifications or standards for data exchange that are not dependent on any proprietary software and are universally understood and accepted for data exchange [7].

\section{Objective}

Despite health information standards being seen as fundamental to the development of interoperable solutions [8,9], their adoption remains to be frustratingly low among information technology (IT) vendors and health organizations [10]. Prior studies have shown that the adoption of such standards in health care organizations is scarce [11-13]; however, there has been some exploration into the adoption of information standards not just in the health care sector. According to the results of these studies, different adoption factors may lead to difficulties for decision makers to explicitly understand, measure, and decrease inhibiting factors or enhance facilitating forces [14]. Hence, there is a need to synthesize those insights to provide decision makers with a holistic view of the adoption of health information standards. To achieve this goal and bridge the research divide, a comprehensive framework of factors that influence the adoption of health information standards is synthesized in this paper. The synthesized framework provides policy and decision makers with a more informed understanding of the factors that hinder or facilitate the adoption of health information standards, enabling better judgement and development of suitable strategies for adoption intervention. The following research questions (RQs) were proposed in this study :

- RQ1: What common factors have been included in previous studies that influence the adoption of health information standards by health care organizations?

- RQ2: Is there a framework that contains these factors more comprehensively from different dimensions?

- RQ3: If so, how will the adoption factors, included in the presented comprehensive framework, specifically affect the adoption of health information standards by health care organizations?
To answer these questions, this study aimed to identify and review existing articles on the adoption of information standards, extracting and summarizing their adoption factors to create a synthesized framework of the factors that affect the adoption of health information standards by health care organizations. A substantial number of stakeholders, including policy makers, citizens/patients, health care IT vendors, health care business owners, assessment bodies and regulators, clinicians and health care professionals, authorities and public administration departments, funders and health insurance companies, and academic departments, will find the presented framework beneficial in practice and when considering future research directions.

\section{Methods}

\section{Study Design}

A systematic review and framework synthesis were used as the methodological underpinning for our study. The systematic review was conducted according to the Preferred Reporting Items for Systematic Reviews and Meta-Analyses (PRISMA) [15], whereas the best fit framework synthesis approach, proposed by Booth and Carroll [16], was adopted. The best fit approach is a relatively recent development, adapted from framework analysis, which involves systematically organizing data into an a priori conceptual framework. This study employed this approach for 2 reasons. First, the technology-organization-environment (TOE) framework, proposed by Tornatzky and Fleischer [17], seen as the most suitable framework for understanding technology adoption in organizational contexts, can be used as an a priori framework to integrate the factors that influence the adoption of health information standards. Second, although the approach is largely deductive (testing a framework), it also includes an inductive (thematic) analysis that is useful in understanding the phenomenon, especially the adoption of information standards from a health care perspective. Thus, this study will use the best fit approach to synthesize a comprehensive framework of factors affecting the adoption of health information standards by organizations based on the retrieved literature.

\section{Search Strategy}

This study comprehensively searched for all relevant literature in 3 electronic databases: Web of Science, Scopus, and PubMed. The search strategy employed is described in the following sections.

\section{Web of Science}

The Web of Science database was searched on July 25, 2019, and included 216 documents. The keywords used were as follows:

$\mathrm{TS}=$ ("information" OR "data") AND TI=("standards") AND $\mathrm{TI}=$ ("adopt*" OR “accept*" OR “implement*”) AND TS=("factors" OR "determinants" OR "barriers" OR "facilitators")

\section{LANGUAGE=English}




\section{Scopus}

The Scopus database was searched on July 25, 2019, and included 209 documents. The keywords used were as follows:

(TITLE-ABS-KEY("information" OR “data") AND TITLE("standards") AND TITLE("adopt*” OR "accept*” OR "implement*") AND TITLE-ABS-KEY("factors" OR "determinants" OR "barriers" OR "facilitators"))AND (LIMIT-TO(LANGUAGE, "English”))

\section{PubMed}

The PubMed database was searched on July 25, 2019, and included 36 documents. The keywords used were as follows:

((((information OR data)) AND standards[Title]) AND (adopt*[Title] OR accept*[Title] OR implement*[Title])) AND (factors OR determinants OR barriers OR facilitators). Filters: English

\section{Inclusion Criteria}

Studies were considered eligible (1) if they were related to the adoption of protocol, data sets, classification, coding, specification, terminology, identification, system framework, assessment, and other information or data standards; (2) if they involved research into the factors (including barriers and facilitators) that influence the adoption or implementation of standards; and (3) if they were based on relevant adoption theories, models, or frameworks, or if they involved the proposal of an adoption model or framework.

\section{Exclusion Criteria}

Studies considered ineligible for this research included those that (1) were not focused on the adoption of information or data standards; (2) did not involve factors that influenced standard adoption; or (3) did not involve relevant adoption theories, models, or frameworks.

\section{Study Selection}

In this study, search results were exported and indexed in EndNote X9.2, a reference management software. Once duplicates and patent documents were removed, LH screened the titles and abstracts of all remaining records for relevance. In the next step, the full-text articles of the retrieved results were examined by LH and JL for inclusion. Discrepancies were adjudicated by a senior researcher (JM).

\section{Data Extraction and Synthesis}

In this study, the best fit framework synthesis approach was followed, which integrates a thematic analysis to synthesize a comprehensive framework. The process consisted of the following stages:

1. Familiarization with collected data. On the basis of the understanding of the terminologies or terms used in the included studies, the factors influencing the adoption of information standards were initially extracted.

2. Generation of initial codes. According to definitions used in the identified studies, the extracted adoption factors were examined successively to make necessary mergers and trade-offs, generating a list of factors appropriate for health information standard adoption scenarios. The process included the following situations: (1) the factors with the same or similar meanings were combined into the same one and named with the most common term used in the literature; (2) the factors with different meanings were considered as juxtaposed dissimilar ones; and (3) if one factor was subordinate to another, the former was subsumed into the latter. For instance, expected benefits had the same meaning as relative advantage; these were combined into the same factor and named the latter. Similarly, government support, vendor support, and partner support were all related to external support, with the first three being subsumed into the last.

3. Search for themes and define and name themes. This stage consisted of 2 steps. First, the 3 dimensions of the prior framework (TOE) were used as initial themes for a deductive analysis, that is, based on the perceived commonality of the themes, the factors were analyzed and organized into 3 dimensions: technology, organization, and environment. The TOE framework explains that an organization's decision to adopt technology can be jointly explained by 3 comprehensive dimensions, including technological, organizational, and environmental contexts. The technological context is essentially described by depicting the important attributes of the technology. The organizational context is depicted using descriptive measures concerning the organization (eg, scope, size, and managerial structure) and is influenced by formal and informal intraorganizational mechanisms for communication and control. The resources and innovativeness of the organization also play a role. The environmental context refers to the different attributes of the external environment in which an organization operates [18]. In the second step, apart from the 3 dimensions, another cluster of adoption factors, which could not be mapped against the TOE framework, was identified. The factors in this cluster were subsequently inductively analyzed, and a new dimension, titled interorganizational relationships, was generated. The interorganizational relationships are concerned with relationships between and among organizations, and it is a complex concept including many aspects, such as partner uncertainty, power, trust, and intermediary of relationship.

4. Review themes. This stage consisted of 2 levels. First, reviewing at the level of coded data. All adoption factors were reanalyzed within and across the dimensions to ensure consistency and independence. Second, reviewing at the level of themes. The dimensions were reviewed one final time to ensure they reflected the meaning of the adoption factors.

Ultimately, a comprehensive framework containing 4 dimensions (ie, technology, organization, environment, and interorganizational relationships) was synthesized. Throughout the synthesis, to ensure consistency in the classification of adoption factors, 3 researchers ( $\mathrm{LH}$, JL, and JM) discussed the factors to eliminate divergence. 


\section{Results}

\section{Search Results}

In this study, 461 records were retrieved from the ISI Web of Science, Scopus, and PubMed databases. After removing 162 duplicate and 26 patent documents, the remaining 273 records were screened based on their titles and abstracts, according to the inclusion and exclusion criteria. As a result, 223 articles were deemed ineligible and were excluded. Then, after examining the full texts of the remaining 50 articles, 35 met the inclusion criteria and were included in the final review. Articles were excluded for the following reasons: 2 studies did not focus on the adoption of information or data standards; 2 studies did not involve factors that influence adoption; 2 studies were presented without relevant adoption theories, models, or frameworks; and 9 studies were not available in full. A flowchart summary of the literature search conducted is presented in the PRISMA diagram shown in Figure 1.

Figure 1. The Preferred Reporting Items for Systematic Reviews and Meta-Analyses flow diagram.

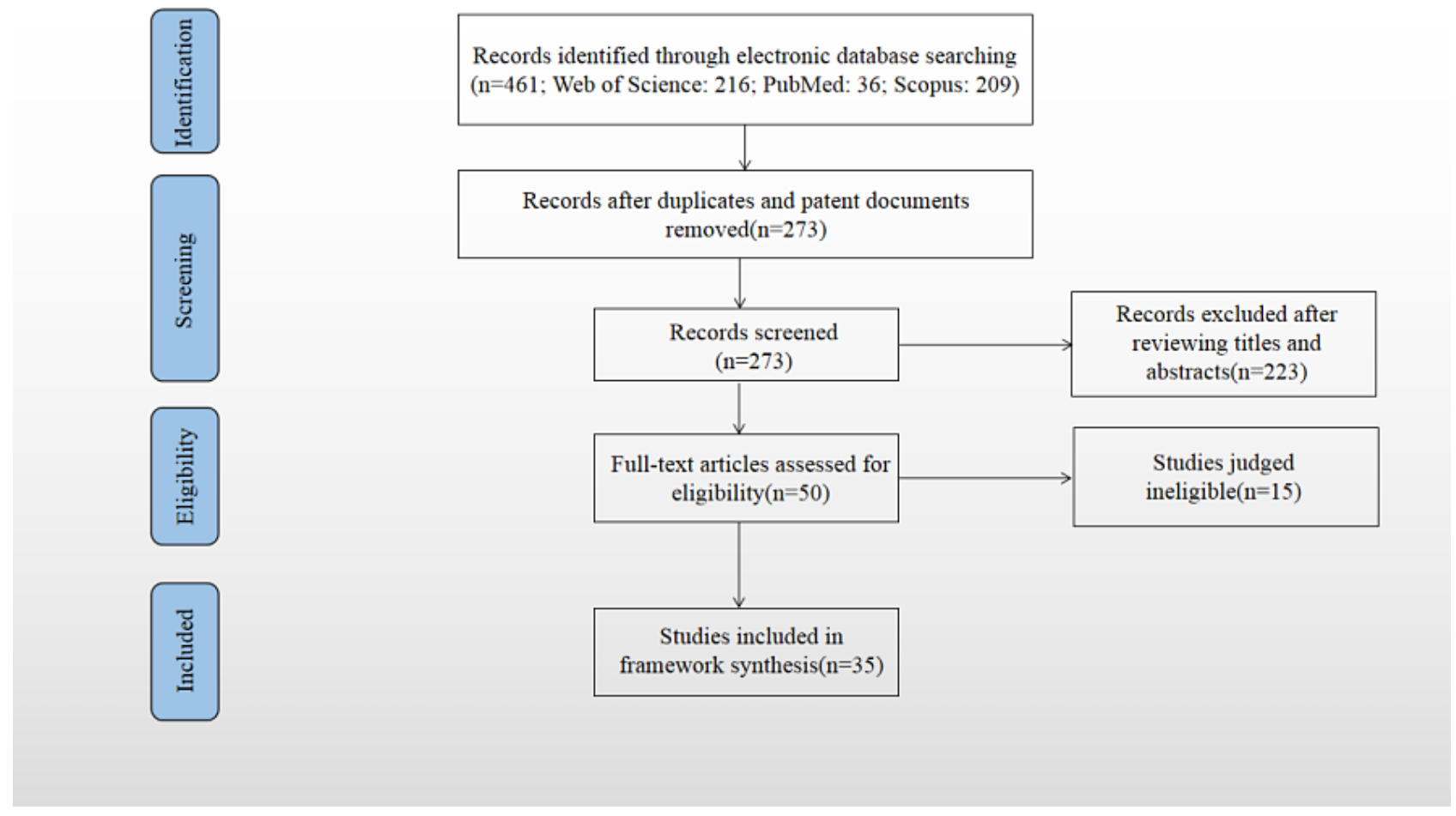

\section{Characteristics of Included Studies}

The 35 articles included in this synthesis were mainly published from 2010 to 2018 (24/35, 68\%). Among the included studies, 19 employed a quantitative design, 15 were qualitative, and 1 adopted a mixed methods approach. The quantitative studies mainly employed a questionnaire or survey, whereas the qualitative studies largely used interviews and focus group discussions. Eight studies were related to the adoption of information standards in the medical field, such as Health Level seven [13], health data standards $[12,19,20]$, and data protection standards [21]. The remaining 27 focused on the IT field. For example, Internet Protocol version 6 [22-24], RosettaNet [25-27], and electronic data interchange [28-30]. Only 13 articles comprehensively considered the 3 dimensions of technology, organization, and environment [12,13,18,22,25,26,28,30-35], whereas one of them also included interorganizational determinants [28].

\section{Results of Synthesis}

This study took the adopting organization as the unit of analysis. On the basis of the best fit framework synthesis approach, the final synthesized framework included technology, organization, environment, and interorganizational relationships (Figure 2). The technology dimension incorporated relative advantage, complexity, compatibility, trialability, observability, switching cost, standards uncertainty, and shared business process attributes. The organization dimension included organizational scale, organizational culture, staff resistance to change, staff training, top management support, and organizational readiness. The environment dimension contained external pressure, external support, network externality, installed base, and information communication. Finally, the interorganizational relationships dimension included partner trust, partner dependence, relationship commitment, and partner power. These common factors identified in the included studies will have an impact on the adoption of health information standards by health care organizations. The specific impact of these factors will be detailed in the next section. The factors that influence the adoption of health information standards under the 4 dimensions are shown in Table 1 (for the definition of each factor, see Multimedia Appendix 1). 
Figure 2. The synthesized framework.

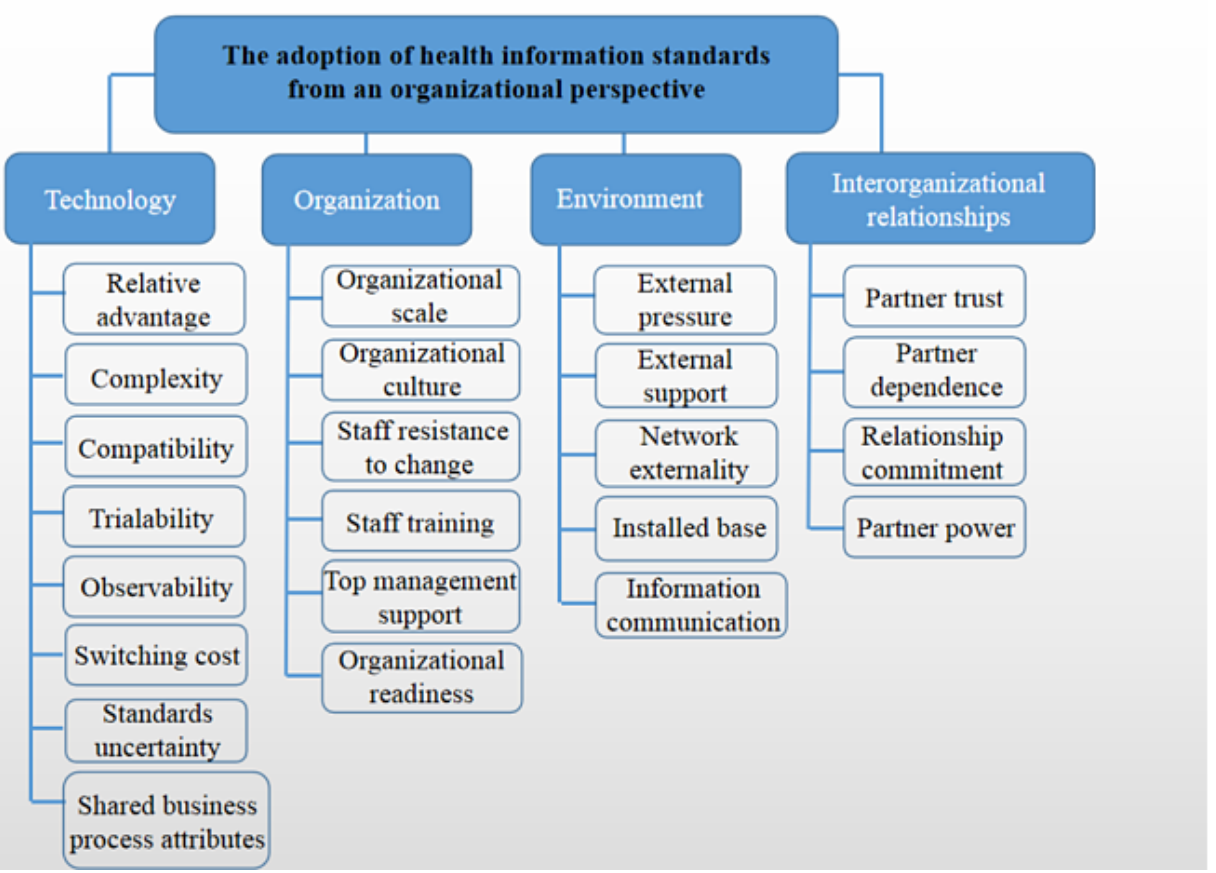


Table 1. Factors that influence the adoption of health information standards under the 4 dimensions.

\begin{tabular}{|c|c|}
\hline Dimensions and factors & References \\
\hline \multicolumn{2}{|l|}{ Technology } \\
\hline Relative advantage & {$[22,24,26,28,30-41]$} \\
\hline Complexity & {$[12,13,22,24,26,28,31-34,36,38,41,42]$} \\
\hline Compatibility & {$[12,13,18,24-26,28,32-36,38,41,42]$} \\
\hline Observability & {$[24,26,41,42]$} \\
\hline Trialability & {$[24,26,34,36,41,43]$} \\
\hline Switching cost & {$[12,23,34,44,45]$} \\
\hline Standards uncertainty & {$[25]$} \\
\hline Shared business process attributes & {$[35]$} \\
\hline \multicolumn{2}{|l|}{ Organization } \\
\hline Organizational scale & {$[13,26,28,31,32,38,41]$} \\
\hline Organizational culture & {$[12,25,26,31,41,46]$} \\
\hline Staff resistance to change & {$[12]$} \\
\hline Staff training & {$[18,46]$} \\
\hline Top management support & {$[18,22,26,28,32,35,37,38,40,42,46]$} \\
\hline Organizational readiness & {$[26,28,30-32,34,35,38,40,41,43,44,47,48]$} \\
\hline \multicolumn{2}{|l|}{ Environment } \\
\hline External pressure & {$[18,22,23,27,30,37,43,48-50]$} \\
\hline External support & {$[13,18,23,24,26,27,32,34,38,40,43,46,49]$} \\
\hline Network externality & {$[12,24,28,34,44,45]$} \\
\hline Installed base & {$[24,31,33]$} \\
\hline Information communication & {$[24,50]$} \\
\hline \multicolumn{2}{|l|}{ Interorganizational relationships } \\
\hline Partner trust & {$[26-29,43]$} \\
\hline Partner dependence & {$[28,29]$} \\
\hline Relationship commitment & {$[26,28,29]$} \\
\hline Partner power & {$[26,27]$} \\
\hline
\end{tabular}

\section{Discussion}

\section{Principal Findings}

As identified in the included studies, there exist various objects (standards), fields of inquiry, and methodological approaches when it comes to exploring factors that influence the adoption of health information standards; each study has its own specific object and approach (for details of included studies, see Multimedia Appendix 2). In all studies, the adoption factors were identified and selected according to relevant theories, models, or frameworks and the specific standard. The resulting differences may be partly because of the different characteristics of the adopted standards and their different requirements for the adoption environment. However, the factors that influence their adoption can be useful in better understanding the adoption of health information standards by organizations. This study sought to identify the contributing factors that influence the adoption of health information standards in the health care sector, providing a comprehensive synthesized framework. As

previously mentioned, the adoption factors have been organized into 4 dimensions, as explained in the following sections.

\section{Technology Dimension}

The characteristics of innovation have been frequently studied in research relating to innovation adoption. Whether an innovation can be adopted by an individual, organization, or industry and its own characteristics and advantages, namely, its own technical factors, play a pivotal role. Therefore, the technical factors of the adopted standards are the primary consideration for the adoption of health information standards. The results of this study indicate that 19 studies used factors of technical characteristics for assessing the impact on adopting information standards [12,13,18,22-26,28,30-43,45]. In this study, relative advantage, complexity, compatibility, trialability, observability, switching cost, standards uncertainty, and shared business process attributes were included in the synthesized framework. 
Roger identified 5 perceived attributes of an innovation that may determine the innovation's rate of adoption [51]. These attributes are relative advantage, complexity, compatibility, trialability, and observability, which are deemed useful for assessing the decision to adopt standards. The degree of relative advantage may be measured in economic terms, such as faster development, less maintenance, and cost saving [41]; these advantages could generate new markets, products, and services, which in turn create a competitive advantage for early adopters [24]. Thus, the greater the perceived relative advantage of the standard, the more rapid its rate of adoption will be [41]. The increased complexity of each standard increases the effort required to implement it and, therefore, reduces the number of potential adopters [24]. Thus, the more complex a standard, the less likely it is to be adopted by the organization. If the adopted standard is compatible with existing technologies or infrastructure, and consistent with past experiences of the organization, the organization will tend to upgrade to the new standard to gain a competitive advantage. Furthermore, if the adopted standard is of high trialability, the organization can reduce uncertainty and the risk of deploying the standard and obtain an increased perceived value through an initial pilot study, which will increase the organization's willingness to adopt the standard. Similarly, if the adopted standard has significant observable benefits and quantifiable advantages, it will reduce the perceived risk and make the organization more willing to adopt the standard. In summary, when the adoption of standards is perceived as having greater relative advantage, compatibility, trialability, observability, and less complexity, the organization will be more inclined to adopt standards $[24,26,41]$.

The cost of switching between standards was observed as a negative factor to standard adoption by health care organizations $[12,23,34]$. Cost is typically associated with the unfamiliarity of the organization with existing resources and skills regarding the standards. For example, if there is a lack of experts who can deal with or lead the adoption, then it will cost large sums to consult relevant experts. As a result, a great deal of staff training, and a high degree of change management, will be required. Mapping issues from the old information infrastructure to the new standardized one will also be a real cost concern; thus, the organization will consider that it has already invested in their current infrastructure and will be reluctant to discard an amount of capital and equipment, as a result of the requirements of adopting the new standard [12].

Standards uncertainty represents the perception of whether the process specifications and associated technologies will be stable, over a certain period, and able to deliver the intended benefits [25]. As David and Greenstein [52] noted, a firm may not be willing to adopt a standard until it becomes a de facto standard in the industry. Thus, if decision makers perceive that the technology and processes required for standard adoption are not stable and are not going to change in the future, this will hinder the adoption of standards by organizations. Finally, as adopted standards are often based on business processes and information sharing between organizations, shared business process attributes, such as transaction volume needs, timeliness of exchange, effectiveness of communications, accuracy and integrity needs, and collaboration levels between participants, will influence the organization's decision on whether to adopt the standards or not [35].

\section{Organization Dimension}

Choosing whether to adopt standards or not is an organizational-level decision executed in an interorganizational context. There are various aspects of standard adoption that cannot be explained by technical factors alone [28]. Although the adoption of health information standards will promote better information sharing and connectivity within and between organizations, there are certain risks and uncertainties in adoption behavior because of past experiences; hence, organizational factors play a significant role in decision making. On the basis of our findings, 19 studies used organizational characteristic factors to assess the impact of adopting information standards $[12,13,18,22,25,26,28,30-35,37,38$, 40-43,46-48]. In this study, organizational scale, organizational culture, staff resistance to change, staff training, top management support, and organizational readiness were included in the synthesized framework.

Organizational size makes a significant contribution to the adoption of standards [13,26,28,31,32,38,41]. According to some prior studies, large enterprises have several advantages over smaller ones. Large enterprises command considerable funds, talent, and research and development capacity, so they can realize the envisaged benefits quickly after adoption. On the contrary, other studies suggest that the bureaucracy of large enterprises is more complex and requires more time for decision making. Small- and medium-sized enterprises are effective and more conducive to adopting new technologies because of their efficient top-down introduction process; however, examination of the introduction effect may require further analysis to determine this conclusion.

Organizations that have a culture of innovation are more likely to experiment with standards at earlier stages [41]. Similarly, organizations should seek to strengthen internal knowledge management practices by constructing a learning organization, as knowledge management enables the knowledge of employees to evolve into the knowledge of the organization and teams. Organizations with rich knowledge of standard adoption are more likely to make decisions quicker and more effectively [31]. Furthermore, an organization's willingness to share information with its trading partners plays a key role in the success of standard adoption [26]. In short, organizations with a culture of innovation, learning, and information sharing are more likely to be early adopters of standards $[12,25,26,31,41,46]$.

Alkraiji et al [12] established that employee reactions are a barrier to the adoption of health information standards because of the lack of understanding of the importance and benefits brought by standards. In addition, the staff's resistance to change also comes from their lack of relevant technical knowledge and ability. Sobol et al [53] indicated that the IT knowledge and capabilities of employees critically influence medical computerized system implementation; in other words, if the staff were more knowledgeable about standards, there would 
be fewer advocator obstacles and less resistance against adoption.

Training is also deemed an important organizational mechanism that contributes to implementation success [54,55]. Employees must acquire new knowledge based on the understanding of the need for change to be able to overcome knowledge barriers and thus adopt new innovations effectively. Having an adequate training program is likely to increase employees' confidence and reduce resistance to standard adoption [56]. Moreover, training has been proven to enhance employee productivity and assist in utilizing the innovation to its full potential, which in turn can help organizations realize the full benefits derived from an innovation [57,58]. Therefore, the development of staff training effectively improves employees' relevant skills, capabilities, and knowledge of standard adoption, thus promoting the adoption process $[18,46]$.

Previous studies have shown that top management support has a positive effect on technology adoption $[13,59,60]$. Senior managers can provide a long-term strategic vision, initiatives, and commitment to create a positive environment suitable for change [61]. Top management support can also enhance work satisfaction by modifying the rules and procedures that regulate and motivate employees' behavior to overcome the resistance to innovation implementation [62]. Young and Poon [63] asserted that top-level management support is essential in promoting interest and employees' satisfaction with the innovation. In the context of standard adoption, a high level of top management support means that top managers understand the benefits associated with the standard and demonstrate their commitment and political support. Therefore, top management support is expected to have a positive effect on standard adoption [18,22,26,28,32,35,38,42,46].

The success of innovation adoption is further dependent on an organization's preparation for the innovation. Organizational readiness, including technology readiness and resource readiness, can be used to measure an organization's capabilities for innovation adoption. Technology readiness refers to the level of sophistication of IT usage and management in an organization [35]. It includes top-level support from managers for related technologies [64], IT personnel, professional knowledge, skills, and experiences required for standard adoption [28,41]. Resource readiness measures whether an organization has enough resources to undertake the adoption [65]. It includes available financial resources to pay for installation costs, implementation of any subsequent enhancements, and ongoing expenses during usage [35], as well as other necessary resources, such as human resources, material resources, and information resources. If an organization has a high level of technology and resource readiness, it will have sufficient capacity to adopt standards, which will enable the organization to make decisions on standard adoption [26,28,30-32,34,35,38,41,43,48].

\section{Environmental Dimension}

All organizations exist in a certain social environment and will inevitably be affected by various external factors. When it comes to the adoption of health information standards, environment is a force that can encourage or impede an organization to adopt standards [28]; thus, environmental factors are also important factors that cannot be ignored. On the basis of the data extracted from the literature, 23 studies used environmental characteristic factors to assess the impact of adopting information standards $[12,13,18,22-28,30-35,37,38,40,42,43,45,46,48-50]$. In this study, external pressure, external support, network externality, installed base, and information communication were included in the synthesized framework.

An organization's decision to adopt standards is stimulated by pressures from various external sources, including the government [66-68], the industry in which it operates (ie, business partners and/or competitors) [69-71], and other sources, such as suppliers, customers, regulatory agencies, and professional associations [18]. Under the stimulation of these pressures, organizations may adopt relevant standards to seek sustainable development or actively strive for market competitiveness [18,22,23,27,30,43,48-50].

The level of external support is critical to the adoption of standards [13,18,23,24,26,27,32,34,38,43,46,49]. Morison [72] concluded that it is difficult for an organization to adopt a new standard without the intervention of an external agent in a position of power. Here, external support includes that from the government [30,73-75], which refers to governmental support for standard adoption through financial incentives, tax cuts, and pilot programs [49] and other forms of support that come from suppliers, external experts, and consultants [18,38,49], which will provide the organization with the necessary assistance and impetus to adopt standards.

Network externalities is one of the 2 main theories used within the stream of an economics perspective of standards and is related to the benefits created through the adoption of new standards by the potential community of adopters [12]. Positive network externalities provide support to the expectations of widespread adoption of a standard. Typically, the result is a reduction in cost because of the economies of scale and synergies created through increased opportunities of interactions among adopters [24]. As more organizations adopt the standard, barriers to adoption for others in the community are lowered [76,77]; thus, the network externalities have a positive influence on organizations to adopt standards [12,24,28,34].

In an internet environment that emphasizes interoperability, the large existing installed base and the resulting inertia (perception of switching costs and sunk costs) have a significant negative impact on the adoption of standards by organizations $[24,31,33]$. Farrell and Saloner [78] suggested that the current state of infrastructure, characterized by its installed base, the resulting inertia, and sunk costs in existing technology, can play an important role in determining the attractiveness of the environment for adoption. A well-established standard with a large installed base can create high drag and inertia, making the environment less attractive, thereby deterring organizations from adopting the new standard [24].

For an innovation to be adopted, information about it must be available to potential adopters $[79,80]$. The extent of information availability will depend on the level and nature of communication within the industry [81]. An environment with successful adoption cases and pioneering adopters can provide 
favorable preconditions for information communication among organizations, thus raising awareness and encouraging innovation adoption [82]. Researchers view communication as vital to encourage the voluntary adoption of a new technology; this is because of a voluntary environment, where the lack of information might prompt other organizations to view the technology as risky, which fights against adoption [50]. Therefore, the effective communication of information relating to standards will play a positive role in propelling standard adoption by organizations $[24,50]$.

\section{Interorganizational Relationships Dimension}

As the adoption of health information standards requires cooperation between two organizations, the relationship between an organization and its partner is salient [28]. In a technologically mature society, technology outsourcing becomes a prevalent method of satisfying an organization's technology needs. Technical issues become relatively insignificant compared with the interorganizational relationships in information standard adoption [83,84]. The major challenge is to build new electronic relationships $[70,85]$. Of the 35 included studies, 5 used factors of interorganizational relationships in assessing the impact on information standard adoption, which were grouped into a new dimension in this study [26-29,43]. Partner trust, partner dependence, relationship commitment, and partner power were included in the synthesized framework.

The trust between organizations lowers stress and improves adaptability [86]. In addition, information exchange is facilitated, and the effectiveness of joint problem solving is improved [87]. According to Shang et al [88], trust was an important factor in explaining interorganizational relationships. When business partners collaborated in their supply chains, an organization that trusted its partners was more likely to reach a consensus in terms of achievable benefits by the adoption of standards [27]. Thus, partner trust facilitates the adoption of standards by organizations [26-29,43].

Interdependence results from a relationship in which both organizations perceive mutual benefits from interaction [89] and in which any loss of autonomy will be equitably compensated through the expected gains. Both parties recognize that the advantages of interdependence provide benefits greater than those that either parties could attain by themselves [90]. Therefore, the interdependence will enable the partners to rely on each other and benefit from the adoption of standards based on a high degree of cooperation, which will facilitate the adoption of standards by organizations [28,29].

Another important antecedent for promoting standard adoption includes partner commitment to the trading relationship [29]. Commitment represents the willingness of trading partners to make efforts toward the relationship. Information standards requires a richer, more cooperative relationship [91]. The standard adopters working collectively with their trading partners can provide better service to customers (or suppliers), thereby increasing their market share [29]. Hence, if the partners can take coordinated actions, based on commitment to the relationship, it will be beneficial for both parties to reach a consensus on the adoption of standards [26,28,29].
It is possible that an organization may exert pressure on its trading partners to adopt standards based on partner power $[26,27]$. Partner power is defined as the capability of an organization to exert an influence on another organization to act in a prescribed manner [92]. Therefore, it is possible that in an interorganizational relationship, organizations with larger partner power can use compulsory or convincing power over their business partners in the adoption of standards [93].

The aforementioned factors that influence the adoption of information standards are extracted from the retrieved literature. The careful and comprehensive consideration and categorization of these factors yield a conceptual framework that can be used as a model for the adoption of health information standards, while remaining subject to adjustment and customization according to specific health information standards and the environment in which they are adopted. The adoption of health information standards can be illustrated in this conceptual framework against 4 dimensions: technological, organizational, environmental, and interorganizational relationships. Any consideration from a single perspective could be biased and fail to provide an accurate delineation of the phenomenon. However, it is worth noting that the synthesized conceptual framework was developed based on an extensive literature review related to information standard adoption and is currently in a preliminary stage. The relationships between the 4 dimensions contained in the framework and the relationships between the adoption factors and the adoption of health information standards by health care organizations can be examined through further empirical studies.

\section{Limitations}

This study has some limitations that should be acknowledged. First, because of the broad connotation of information standards, the search strategy employed in this study did not fully cover all concepts of information standards, which may lead to potential articles not being identified. Furthermore, because of resource constraints, the databases retrieved in this study were limited, which may result in other relevant studies not being retrieved. Second, this study excluded articles that did not involve relevant adoption theories, models, or frameworks and may have omitted some articles that solely proposed adoption factors. Finally, because of the overlap and intersection between the concepts of the adoption factors involved in the literature, there exists some subjectivity and bias in the concept definition and selection of factors and organizing the factors into corresponding dimensions in the synthesized framework.

In view of the above limitations, the synthesized framework may not include all possible adoption factors, which should be further improved and supplemented by research in the future. Nevertheless, this study has fully considered the factors that influence the adoption of health information standards, and the comprehensive framework provides references for future research and insights into the formulation and adoption of health information standards.

\section{Conclusions}

This study has comprehensively reviewed the factors that influence the adoption of information standards in the published 
literature. A synthesized framework of integrated factors that influence the adoption of health information standards by organizations was extracted and presented.

This study delivers contributions at different levels. First, at the theoretical level, the synthesized framework has addressed knowledge gaps in the adoption of health information standards in health care organizations. Second, at the practice level, it will help guide policy and decision makers in better judging and developing suitable strategies for adoption interventions. For health care organizations, in particular, strategies for the adoption interventions include upgrading infrastructure and enriching technical resources and skills to better adapt to new standards; establishing an innovative culture, strengthening staff training, raising the attention of top managers, and increasing the investment of technology and resources to promote the implementation of new standards; heading on competitive pressure, leveraging external forces and information communication channels, and overcoming the industry inertia to actively respond to the adoption of new standards; and establishing trust and interdependency relationships among partners based on commitment and making reasonable use of partner power to create the industry fashion of standard adoption. Furthermore, it also provides directions for future research to enrich the factors that influence the adoption of relevant standards or health care technologies.

\section{Acknowledgments}

This work was supported by the Fundamental Research Funds for the Central Universities (HUST: 2019WKYXZX010).

\section{Conflicts of Interest}

None declared.

\section{Multimedia Appendix 1}

The definition of each factor.

[DOCX File, 16 KB-Multimedia Appendix 1]

\section{Multimedia Appendix 2}

Details of included studies.

\section{[DOCX File , $40 \mathrm{~KB}-$ Multimedia Appendix 2]}

\section{References}

1. Plsek PE, Greenhalgh T. Complexity science: The challenge of complexity in health care. Br Med J 2001 Sep 15;323(7313):625-628 [FREE Full text] [doi: 10.1136/bmj.323.7313.625] [Medline: 11557716]

2. Hakkinen H, Turunen P, Spil T. Information in Health Care Process - Evaluation Toolkit Development. In: Proceedings of the 36th Annual Hawaii International Conference on System Sciences. 2003 Presented at: HICSS'03; January 6-9, 2003;

Big Island, HI, USA URL: https://ieeexplore.ieee.org/stamp/stamp.jsp?tp=\&arnumber=1174362\&tag=1

3. Khoumbati K, Themistocleous M. Integrating the IT infrastructures in healthcare organisations: a proposition of influential factors. Electron J Gov 2006 Jan;4(1):27-36 [FREE Full text]

4. Chaudhry B, Wang J, Wu S, Maglione M, Mojica W, Roth E, et al. Systematic review: impact of health information technology on quality, efficiency, and costs of medical care. Ann Intern Med 2006 May 16;144(10):742-752. [doi: 10.7326/0003-4819-144-10-200605160-00125] [Medline: 16702590]

5. Park H, Hardiker N. Clinical terminologies: a solution for semantic interoperability. J Korean Soc Med Inform 2009 Mar;15(1):1-11. [doi: 10.4258/jksmi.2009.15.1.1]

6. Zhang Y, Xu Y, Shang L, Rao K. An investigation into health informatics and related standards in China. Int J Med Inform 2007 Aug;76(8):614-620. [doi: 10.1016/j.ijmedinf.2006.05.003] [Medline: 16793329]

7. Thomas JW. Loughborough University. 2018. The Adoption and Diffusion of Data-exchange Standards URL: https://hdl. handle.net/2134/34998 [accessed 2019-08-20]

8. Kahn MG, Bailey LC, Forrest CB, Padula MA, Hirschfeld S. Building a common pediatric research terminology for accelerating child health research. Pediatrics 2014 Mar;133(3):516-525 [FREE Full text] [doi: 10.1542/peds.2013-1504] [Medline: 24534404]

9. Berler A, Tagaris A, Angelidis P, Koutsouris D. A roadmap towards healthcare information systems interoperability in Greece. J Telecommun Inf Technol 2006;2006(2):59-73 [FREE Full text] [doi: 10.1117/12.2191918]

10. Hammond WE. The making and adoption of health data standards. Health Aff (Millwood) 2005;24(5):1205-1213. [doi: 10.1377/hlthaff.24.5.1205] [Medline: 16162564]

11. Olsen J, Baisch MJ. An integrative review of information systems and terminologies used in local health departments. J Am Med Inform Assoc 2014 Feb;21(e1):e20-e27 [FREE Full text] [doi: 10.1136/amiajnl-2013-001714] [Medline: 24036156]

12. Alkraiji AI, Jackson T, Murray I. Factors impacting the adoption decision of health data standards in tertiary healthcare organisations in Saudi Arabia. J Ent Inf Manag 2016 Sep;29(5):650-676. [doi: 10.1108/jeim-11-2014-0111] 
13. Lin C, Lin I, Roan J, Yeh J. Critical factors influencing hospitals' adoption of HL7 version 2 standards: an empirical investigation. J Med Syst 2012 Jun;36(3):1183-1192. [doi: 10.1007/s10916-010-9580-2] [Medline: 20827568]

14. Li J, Talaei-Khoei A, Seale H, Ray P, Macintyre CR. Health care provider adoption of eHealth: systematic literature review. Interact J Med Res 2013 Apr 16;2(1):e7 [FREE Full text] [doi: 10.2196/ijmr.2468] [Medline: 23608679]

15. Moher D, Liberati A, Tetzlaff J, Altman DG, PRISMA Group. Preferred reporting items for systematic reviews and meta-analyses: the PRISMA statement. Ann Intern Med 2009 Aug 18;151(4):264-9, W64. [doi: 10.7326/0003-4819-151-4-200908180-00135] [Medline: 19622511]

16. Booth A, Carroll C. How to build up the actionable knowledge base: the role of 'best fit' framework synthesis for studies of improvement in healthcare. BMJ Qual Saf 2015 Nov;24(11):700-708 [FREE Full text] [doi: 10.1136/bmjqs-2014-003642] [Medline: 26306609]

17. Tornatzky LG, Fleischer M. Processes of Technological Innovation. Lexington, MA: Lexington Books; 1991.

18. Vatanasakdakul S, Aoun C, Chen Y. Chasing success: an empirical model for IT governance frameworks adoption in Australia. Sci Technol Soc 2017;22(2):182-211. [doi: 10.1177/0971721817702278]

19. Alkraiji A, Jackson T, Murray I. Barriers to the widespread adoption of health data standards: an exploratory qualitative study in tertiary healthcare organizations in Saudi Arabia. J Med Syst 2013 Apr;37(2):9895. [doi: 10.1007/s10916-012-9895-2] [Medline: 23321966]

20. Alkraiji A, Jackson T, Murray I. Health data standards and adoption process: Preliminary findings of a qualitative study in Saudi Arabia. Campus Wide Inf Syst 2011;28(5):345-359. [doi: 10.1108/10650741111181616]

21. Foth M, Schusterschitz C, Flatscher - Thöni M. Technology acceptance as an influencing factor of hospital employees' compliance with data - protection standards in Germany. J Public Health 2012;20(3):253-268. [doi: 10.1007/s10389-011-0456-9]

22. Wang X, Zander S. Extending the model of internet standards adoption: A cross-country comparison of IPv6 adoption. Inf Manag 2018 Jun;55(4):450-460. [doi: 10.1016/j.im.2017.10.005]

23. Hovav A, Hemmert M, Kim YJ. Determinants of internet standards adoption: The case of South Korea. Res Policy 2011 Mar;40(2):253-262. [doi: 10.1016/j.respol.2010.09.016]

24. Hovav A, Patnayakuni R, Schuff D. A model of internet standards adoption: the case of IPv6. Inform Syst J 2004;14(3):265-294. [doi: 10.1111/j.1365-2575.2004.00170.x]

25. Venkatesh V, Bala H. Adoption and impacts of interorganizational business process standards: Role of partnering synergy. Inf Syst Res 2012 Dec;23(4):1131-1157. [doi: 10.1287/isre.1110.0404]

26. Chan FT, Chong AY. A SEM-neural network approach for understanding determinants of interorganizational system standard adoption and performances. Decis Sup Syst 2012 Dec;54(1):621-630. [doi: 10.1016/j.dss.2012.08.009]

27. Yee - Loong Chong A, Ooi K. Adoption of interorganizational system standards in supply chains: An empirical analysis of RosettaNet standards. Indus Manag Data Syst 2008;108(4):529-547. [doi: 10.1108/02635570810868371]

28. Huang Z, Janz BD, Frolick MN. A comprehensive examination of internet-EDI adoption. Inf Syst Manag 2008;25(3):273-286. [doi: $10.1080 / 10580530802151228$ ]

29. Lee S, Lim GG. The impact of partnership attributes on EDI implementation success. Inf Manag 2003 Dec;41(2):135-148. [doi: 10.1016/s0378-7206(03)00043-0]

30. Kuan KK, Chau PY. A perception-based model for EDI adoption in small businesses using a technology-organization-environment framework. Inf Manag 2001 Oct;38(8):507-521. [doi: 10.1016/s0378-7206(01)00073-8]

31. Hu C. Main Factors Affecting the Adoption and Diffusion of Web Service Technology Standards. In: Proceedings of the International Conference on Information and Management Engineering. 2011 Presented at: ICCIC'11; September 17-18, 2011; Wuhan, China p. 81-87. [doi: 10.1007/978-3-642-24091-1 12]

32. Burbano A, Rardin R, Pohl E. Exploring the Factors Affecting the Identification Standards Adoption Process in the US Healthcare Supply Chain. In: 2011 Proceedings of PICMET'11: Technology Management in the Energy Smart World. 2011 Presented at: PICMET'11; July 31- August 4, 2011; Portland, OR, USA URL: https://ieeexplore.iee.org/stamp/stamp. jsp?tp=\&arnumber $=6017680$

33. Kelly D, Feller J, Finnegan P. Complex Network-Based Information Systems (CNIS) Standards: Toward an Adoption Model. In: Proceedings of the IFIP International Working Conference on the Transfer and Diffusion of Information Technology for Organizational Resilience. 2006 Presented at: TDIT'06; June 7-10, 2006; Galway, Ireland p. 3-20. [doi: 10.1007/0-387-34410-1 1]

34. Wapakabulo J, Dawson R, Probets S, King T. A Step Towards the Adoption of Data-exchange Standards: A UK Defence Community Case Study. In: Proceedings of the 4th Conference on Standardization and Innovation in Information Technology. 2005 Presented at: SIIT'05; September 21-23, 2005; Geneva, Switzerland. [doi: 10.1109/siit.2005.1563812]

35. Nelson ML, Shaw MJ. IDEALS @ Illinois. 2003. The Adoption and Diffusion of Interorganizational System Standards and Process Innovations URL: http://hdl.handle.net/2142/84534 [accessed 2019-08-20]

36. Ramoni RB, Etolue J, Tokede O, McClellan L, Simmons K, Yansane A, et al. Adoption of dental innovations: The case of a standardized dental diagnostic terminology. J Am Dent Assoc 2017 May;148(5):319-327 [FREE Full text] [doi: 10.1016/j.adaj.2017.01.024] [Medline: 28364948] 
37. Mueller T, Dittes S, Ahlemann F, Urbach N, Smolnik S. Because Everybody is Different: Towards Understanding the Acceptance of Organizational IT Standards. In: Proceedings of the 2015 48th Hawaii International Conference on System Sciences. 2015 Presented at: HICSS'15; January 5-8, 2015; Kauai, HI, USA. [doi: 10.1109/hicss.2015.487]

38. MacLennan E, van Belle J. Factors affecting the organizational adoption of service-oriented architecture (SOA). Inf Syst Bus Manag 2014;12(1):71-100. [doi: 10.1007/s10257-012-0212-x]

39. Singh RM, Dahlin K. Merit, Acceptance or Access: Opposing Forces to Adoption of a New Standard. In: Proceedings of the 5th International Conference on Standardization and Innovation in Information Technology. 2007 Presented at: SIIT'07; October 17-19, 2007; Calgary, AB, Canada. [doi: 10.1109/siit.2007.4629316]

40. Ng CS, Hsu PY, Tsai WH. Salient Factors for Maintenance Standard Adoption in Enterprise Resource Planning Context: An Exploratory Study. In: Proceedings of the 39th Annual Hawaii International Conference on System Sciences. 2006 Presented at: HICSS'06; January 4-7, 2006; Kauia, HI, USA, USA. [doi: 10.1109/hicss.2006.426]

41. Chen M. Factors affecting the adoption and diffusion of XML and Web services standards for E-business systems. Int $\mathbf{J}$ Hum Comput Stud 2003 Mar;58(3):259-279. [doi: 10.1016/s1071-5819(02)00140-4]

42. Velleman EM, Nahuis I, van der Geest T. Factors explaining adoption and implementation processes for web accessibility standards within eGovernment systems and organizations. Univ Access Inf Soc 2017;16(1):173-190. [doi: 10.1007/s10209-015-0449-5]

43. Henning F. Adoption of Interoperability Standards in Government Information Networks: An Initial Framework of Influence Factors. In: Proceedings of the 7th International Conference on Theory and Practice of Electronic Governance. 2013 Presented at: ICEGOV'13; October 22 - 25, 2013; Seoul, Korea p. 264-267. [doi: 10.1145/2591888.2591936]

44. Gong N. Barriers to adopting interoperability standards for cyber threat intelligence sharing: an exploratory study. In: Arai K, Kapoor S, Bhatia R, editors. Intelligent Computing. Cham: Springer; 2018:666-684.

45. Techatassanasoontorn AA, Suo S. Influences on standards adoption in de facto standardization. Inf Technol Manag 2011;12(4):357-385. [doi: 10.1007/s10799-011-0089-2]

46. Ghahramani A. Factors that influence the maintenance and improvement of OHSAS 18001 in adopting companies: A qualitative study. J Clean Prod 2016 Nov;137:283-290. [doi: 10.1016/j.jclepro.2016.07.087]

47. Buyle R, van Compernolle M, Vlassenroot E, Vanlishout Z, Mechant P, Mannens E. 'Technology readiness and acceptance model' as a predictor for the use intention of data standards in smart cities. Media Commun 2018 Dec;6(4):127-139. [doi: 10.17645/mac.v6i4.1679]

48. Veit D, Parasie NP. Common Data Exchange Standards: Determinants for Adoption at the Municipal Level. In: Proceedings of the 2010 Americas Conference on Information Systems. 2010 Presented at: AMCIS'10; August 12-15, 2010; Lima, Peru URL: https://pdfs.semanticscholar.org/c600/9383c722b640f1249885f2e70a1b1459a9bc.pdf

49. Lucho S, Melendez K, Dávila A. Analysis of environmental factors in the adoption of ISO/IEC 29110. Multiple case study. In: Mejia J, Muñoz M, Rocha Á, Quiñonez Y, Calvo-Manzano J, editors. Trends and Applications in Software Engineering. Cham: Springer; Oct 2017:82-93.

50. Azam S. Perceived environmental factors and the intention to adopt a standard business reporting facility: A survey of Australian corporate CFOs. Asian Acad Manag J Account Finance 2014;10(2):147-173 [FREE Full text]

51. Rogers EM. Diffusion of Innovations. Fourth Edition. New York: Free Press; 1995.

52. David PA, Greenstein S. The economics of compatibility standards: an introduction to recent research. Econ Innov New Technol 1990;1(1-2):3-41. [doi: 10.1080/10438599000000002]

53. Sobol MG, Alverson M, Lei D. Barriers to the adoption of computerized technology in health care systems. Top Health Inf Manage 1999 May;19(4):1-19. [Medline: 10387652]

54. Dezdar S, Sulaiman A. Successful enterprise resource planning implementation: taxonomy of critical factors. Indus Manag Data Syst 2009 Sep;109(8):1037-1052. [doi: 10.1108/02635570910991283]

55. Hwang MI, Lin CT, Lin JW. Organizational Factors for Successful Implementation of Information Systems: Disentangling the Effect of Top Management Support and Training. In: Proceedings of the Southern Association for Information Systems Conference. 2012 Presented at: Proceedings of the Southern Association for Information Systems Conference; March 23-24, 2012; Atlanta, GA, USA p. 111-115 URL: https://tinyurl.com/y8su9emh

56. Dezdar S, Ainin S. The influence of organizational factors on successful ERP implementation. Manag Decis 2011;49(6):911-926. [doi: 10.1108/00251741111143603]

57. Liu PL. Empirical study on influence of critical success factors on ERP knowledge management on management performance in high-tech industries in Taiwan. Expert Syst Appl 2011;38(8):10696-10704. [doi: 10.1016/j.eswa.2011.02.045]

58. Tharenou P, Saks AM, Moore C. A review and critique of research on training and organizational-level outcomes. Hum Res Manag Rev 2007 Sep;17(3):251-273. [doi: 10.1016/j.hrmr.2007.07.004]

59. Vykoukal J. Grid Technology as Green IT Strategy? Empirical Results from the Financial Services Industry. In: Proceedings of the 18th European Conference on Information Systems. 2010 Presented at: ECIS'10; June 7-9, 2010; Pretoria, South Africa URL: https://aisel.aisnet.org/cgi/viewcontent.cgi?article=1040\&context=ecis2010

60. Lai H, Lin I, Tseng L. High-level managers' considerations for RFID adoption in hospitals: an empirical study in Taiwan. J Med Syst 2014 Feb;38(2):3. [doi: 10.1007/s10916-013-0003-z] [Medline: 24445396] 
61. Yoon TE, George JF. Why aren't organizations adopting virtual worlds? Comput Hum Behav 2013 May;29(3):772-790. [doi: 10.1016/j.chb.2012.12.003]

62. Purvis RL, Sambamurthy V, Zmud RW. The assimilation of knowledge platforms in organizations: An empirical investigation. Organ Sci 2001 Apr;12(2):117-135. [doi: 10.1287/orsc.12.2.117.10115]

63. Young R, Poon S. Top management support—almost always necessary and sometimes sufficient for success: Findings from a fuzzy set analysis. Int J Proj Manag 2013 Oct;31(7):943-957. [doi: 10.1016/j.ijproman.2012.11.013]

64. Lee JN, Kim YG. Effect of partnership quality on IS outsourcing success: conceptual framework and empirical validation. J Manag Inf Syst 1999;15(4):29-61 [FREE Full text] [doi: 10.1080/07421222.1999.11518221]

65. Swatman PM, Swatman PA. EDI system integration: A definition and literature survey. Inform Soc 1992;8(3):169-205. [doi: 10.1080/01972243.1992.9960119]

66. Teo HH, Tan B, Wei KK. Innovation Diffusion Theory as a Predictor of Adoption Intention for Financial EDI. In: Proceedings of the 16th International Conference on Information Systems. 1995 Presented at: ICIS'95; December 10-13, 1995; Amsterdam, Netherlands p. 155-165 URL: https://pdfs.semanticscholar.org/cdd5/8f260875e98175cb690fa232d0e847a0c2c0.pdf

67. Lippert SK, Govindarajulu C. Technological, organizational, and environmental antecedents to web services adoption. Commun IIMA 2006;6(1):147-160 [FREE Full text]

68. Xu S, Zhu K, Gibbs J. Global technology, local adoption: a cross-country investigation of internet adoption by companies in the United States and China. Electron Mark 2004;14(1):13-24. [doi: 10.1080/1019678042000175261]

69. Bouchard L. Decision Criteria in the Adoption of EDI. In: Proceedings of the 14th International Conference on Information Systems. 1993 Presented at: ICIS'93; December 5-8, 1993; Orlando, Florida, USA p. 365-376 URL: https://pdfs. semanticscholar.org/1900/4658d2e7b34f7ae521a37888da458c6eb2ab.pdf

70. Hart PJ, Saunders CS. Emerging electronic partnerships: antecedents and dimensions of EDI use from the supplier's perspective. J Manag Inf Syst 1998;14(4):87-111 [FREE Full text] [doi: 10.1080/07421222.1998.11518187]

71. Premkumar G, Ramamurthy K. The role of interorganizational and organizational factors on the decision mode for adoption of interorganizational systems. Decis Sci 1995 May;26(3):303-336. [doi: 10.1111/j.1540-5915.1995.tb01431.x]

72. Morison E. Gunfire at sea: a case study of innovation. In: Tushman M, Anderson P, editors. Managing Strategic Innovation and Change. New York: Oxford University Press; 1997:129-140.

73. Thatcher SM, Foster W, Zhu L. B2B e-commerce adoption decisions in Taiwan: The interaction of cultural and other institutional factors. Electron Commer Res Appl 2006 Jun;5(2):92-104. [doi: 10.1016/j.elerap.2005.10.005]

74. Moon MJ, Bretschneider S. Can state government actions affect innovation and its diffusion?: An extended communication model and empirical test. Technol Forecast Soc Change 1997 Jan;54(1):57-77. [doi: 10.1016/s0040-1625(96)00121-7]

75. Kraemer KL, Gurbaxani V, King JL. Economic development, government policy, and the diffusion of computing in Asia-Pacific countries. Public Adm Rev 1992 Mar;52(2):146-156. [doi: 10.2307/976468]

76. Rosenberg N. Inside The Black Box. Cambridge: Cambridge University Press; 1982.

77. Arthur WB. Competing technologies: an overview. In: Dosi G, Freeman C, editors. Technical Change and Economic Theory. London: Pinter Publishers; 1988:590-607.

78. Farrell J, Saloner G. Competition, compatibility, and standards: the economics of horses, penguins and lemmings. In: Gabel HL, editor. Product Standardization and Competitive Strategy. Amsterdam: Elsevier Science; 1986:1-21.

79. Premkumar G, Ramamurthy K, Nilakanta S. Implementation of electronic data interchange: an innovation diffusion perspective. J Manag Inf Syst 1994;11(2):157-186 [FREE Full text] [doi: 10.1080/07421222.1994.11518044]

80. Rogers EM. Diffusion of Innovations. Fifth Edition. New York: Free Press; 2003.

81. Frambach RT. An integrated model of organizational adoption and diffusion of innovations. Eur J Mark 1993 Jun;27(5):22-41. [doi: 10.1108/03090569310039705]

82. Gharavi H, Love PE, Cheng EW. Information and communication technology in the stockbroking industry: an evolutionary approach to the diffusion of innovation. Indus Manag Data Syst 2004 Dec;104(9):756-765. [doi: 10.1108/02635570410567748]

83. King WR, Malhotra Y. Developing a framework for analyzing IS sourcing. Inf Manag 2000 Sep;37(6):323-334. [doi: 10.1016/s0378-7206(00)00046-x]

84. Yang C, Huang J. A decision model for IS outsourcing. Int J Inf Manag 2000 Jun;20(3):225-239. [doi: 10.1016/s0268-4012(00)00007-4]

85. Gottardi G, Bolisani E, Di Biagi M. Electronic commerce and open communities: an assessment of internet EDI. Int J Serv Technol Manag 2004;5(2):151-169. [doi: 10.1504/ijstm.2004.004056]

86. Ouchi W, Williamson OE. Markets and hierarchies: analysis and antitrust implications. Adm Sci Q 1977 Sep;22(3):540. [doi: $10.2307 / 2392191]$

87. Zand DE. Trust and managerial problem solving. Adm Sci Q 1972 Jun;17(2):229-239. [doi: 10.2307/2393957]

88. Shang RA, Chen CC, Liu YC. Internet EDI Adoption Factors: Power, Trust and Vision. In: Proceedings of the 7th international conference on Electronic commerce. 2005 Presented at: ICEC'05; August 15-17, 2005; Xi' an, China p. 101-108. [doi: $\underline{10.1145 / 1089551.1089573]}$

89. Levine S, White PE. Exchange as a conceptual framework for the study of interorganizational relationships. Adm Sci Q 1961 Mar;5(4):583-601. [doi: 10.2307/2390622] 
90. Mohr J, Spekman R. Characteristics of partnership success: Partnership attributes, communication behavior, and conflict resolution techniques. Strat Manag J 1994 Feb;15(2):135-152. [doi: 10.1002/smj.4250150205]

91. Frazier GL, Spekman RE, O'Neal CR. Just-in-time exchange relationships in industrial markets. J Mark 1988;52(4):52-67. [doi: 10.1177/002224298805200406]

92. Ratnasingam P. The influence of power on trading partner trust in electronic commerce. Internet Res 2000 Mar;10(1):56-63. [doi: 10.1108/eum0000000005316]

93. Ke W, Liu H, Wei KK, Gu J, Chen H. How do mediated and non-mediated power affect electronic supply chain management system adoption? The mediating effects of trust and institutional pressures. Decis Sup Syst 2009 Mar;46(4):839-851. [doi: 10.1016/j.dss.2008.11.008]

\author{
Abbreviations \\ HIT: health information technology \\ IT: information technology \\ PRISMA: Preferred Reporting Items for Systematic Reviews and Meta-Analyses \\ RQ: research question \\ TOE: technology-organization-environment
}

Edited by C Lovis; submitted 07.12.19; peer-reviewed by U Taneja, Y Tani, A Rezaei Aghdam; comments to author 01.02.20; revised
version received 16.02.20; accepted 20.02.20; published 15.05.20
Please cite as:
Han L, Liu J, Evans R, Song Y, Ma J
Factors Influencing the Adoption of Health Information Standards in Health Care Organizations: A Systematic Review Based on Best
Fit Framework Synthesis
JMIR Med Inform 2020;8(5):e17334
URL: $\underline{\text { https://medinform.jmir.org/2020/5/e17334 }}$
doi: $\underline{10.2196 / 17334}$
PMID: $\underline{32347800}$

CLu Han, Jing Liu, Richard Evans, Yang Song, Jingdong Ma. Originally published in JMIR Medical Informatics (http://medinform.jmir.org), 15.05.2020. This is an open-access article distributed under the terms of the Creative Commons Attribution License (https://creativecommons.org/licenses/by/4.0/), which permits unrestricted use, distribution, and reproduction in any medium, provided the original work, first published in JMIR Medical Informatics, is properly cited. The complete bibliographic information, a link to the original publication on http://medinform.jmir.org/, as well as this copyright and license information must be included. 